\title{
LA COMUNICACIÓN POLÍTICA EN LA ESPAÑA DEMOCRÁTICA
} (1976-2012)

\section{Pere-Oriol Costa ${ }^{1}$}

Universidad Autónoma de Barcelona

pere.oriol@uab.cat

Material original autorizado para su primera publicación en la revista académica REDMARKA. Revista Digital de Marketing Aplicado. https://doi.org/10.17979/redma.2012.01.08.4735

Recibido: 15 Abril 2012

Aceptado 24 Mayo 2012

\section{Resumen}

La transición española de la dictadura a la democracia permitió el desarrollo de una comunicación política democrática al estilo de la que se venía aplicando en los países europeos más desarrollados y en Norteamérica.

El período se abrió en 1976. Los partidos que concurrieron a las primeras elecciones generales en democracia poseían una nula experiencia en comunicación electoral y en estrategia. Pero desde aquellos momentos iniciales la evolución y la mejora no han cesado, con la incorporación de nuevas técnicas y la utilización transversal de aportaciones de la Publicidad, el Marketing y la Sociología para lograr una comunicación política efectiva.

El objeto de este artículo es la descripción de la forma en que se ha producido esta evolución. Se trata de exponer como ha sido la comunicación política en España desde el 1976 al 2012, con que actores principales se ha contado, que papeles han desarrollado cada uno de ellos y en que marco legal y en que entorno político se ha desarrollado.

Pero antes de acercarnos al objeto de forma sistemática nos parece significativo, por su extravagancia y por su relevancia, fijarnos en un período

\footnotetext{
${ }^{1}$ Catedrático emérito de Comunicación Política de la Universidad Autónoma de Barcelona. Autor de Cómo ganar unas elecciones (Barcelona: Paidós, 2008).
} 
concreto cuyo punto culminante fue el atentado del 11 de marzo en la estación de Atocha que como es sabido provocó caso 200 muertos.

Palabras clave: Comunicación Política, Democracia, España.

\section{Abstract}

POLITICAL COMMUNICATION IN THE DEMOCRATIC SPAIN (1976-2012)

The Spanish Transition from dictatorship to democracy allowed the development of a democratic political communication style which had been applied in European countries developed and in North America.

The period opened in 1976. Parties which attended the first general elections in democracy had zero experience in electoral communication and strategy. But since those initial moments evolution and improvement have not ceased, with the incorporation of new techniques and the transverse use of inputs from the advertising, Marketing and sociology to achieve an effective communication policy.

The subject of this article is the description of the way in which this evolution occurred. It's exposing as it has been the political communication in Spain from 1976 to 2012, with key players has had, that papers have developed each of them and in that framework legal and political environment has developed.

But before approaching the object of form systematics seems significant, by his extravagance and its relevance, look at a particular period whose climax was the attack on March 11 at the station of Atocha that as you know case resulted in 200 dead.

Keywords: Political Communication, Democracy, Spain 


\section{Tres días que cambiaron España}

Durante los días que sucedieron al atentado, el Gobierno de Madrid tuvo un comportamiento sorprendente que rompió con el proceso de desarrollo armónico, de crecimiento y de maduración que había caracterizado hasta entonces el desarrollo de la comunicación política en los años de transición a la democracia. En realidad, la extraña actuación del gobierno era concordante con los que venía haciendo al Partido Popular desde que pudo gobernar con mayoría absoluta a partir del año 2000 y con lo que hizo después, durante los primeros años de gobierno Zapatero, en los que desde la oposición se mostraban actitudes muy radicales en los contenidos y agresivos en la forma. (1)

Para un observador imparcial, el conjunto de declaraciones que difundió el gobierno español desde el mismo momento en que se produjo el atentado del 11-M siguen siendo incomprensibles. Todos los informes que recibía el ministerio del Interior desde la cadena de mando policial y de los agentes desplegados sobre el terreno iban determinando la autoría de integristas musulmanes. Sin embargo el ministro del Interior Ángel Acebes seguía apuntando a ETA como responsable del atentado en todas sus declaraciones del sábado día 13, dos días después de la acción terrorista. La actitud del Gobierno fue más lejos. Su Presidente José María Aznar llamó por teléfono en persona a los directores de los principales diarios afirmando la autoría etarra y provocando, entre otras cosas, que "El País" publicara la portada más errónea de su historia. Desmontando el título que tenían previsto "Matanza terrorista en Madrid" lo cambiaron por "Matanza de ETA en Madrid". Los corresponsales de prensa extranjeros recibieron llamadas de Presidencia del Gobierno induciéndoles a informar sobre la autoría vasca, razón por la cual, días después difundieron una nota conjunta de protesta. Pero lo más grave desde el punto de vista diplomático fue el intento de intoxicar el Consejo de Seguridad de la ONU, que posteriormente obligó a las autoridades españolas a pedir disculpas después de que al menos la mitad de los miembros del Consejo expresaran su malestar por la "precipitación" del Gobierno Español.(2) 
Tres días después del atentado se celebraban elecciones generales. Durante las horas que transcurrieron entre la explosión de las bombas y la apertura de las urnas se registraron movimientos muy interesantes desde el punto de vista la comunicación. Ante la insistencia del ministro de la Gobernación en unas tesis que policialmente no se sostenían y que eran desmentidas por toda la prensa internacional, dos medios de comunicación de los considerados "nuevos" pero que en realidad ya tenían una tasa de penetración muy alta, dieron una prueba muy significativa de su potencial movilizador. Sin que se haya podido determinar un núcleo inicial organizado, aunque algunos señalan el entorno del PSOE, los mensajes enviados por Internet y por los teléfonos móviles, que al final acababan siempre con la palabra ipásalo! consiguieron convocar nutridas manifestaciones en todas las grandes ciudades españolas, las cuales acababan siempre frente a la sede del PP donde los manifestantes reclamaban al Gobierno que dijera la verdad. Esta actitud de descontento y enojo provocó, seguramente un aumento de la participación electoral que afectó a amplios segmento de públicos jóvenes tendentes a la abstención. (3)

Es sabido que el PSOE ganó las elecciones del 14 de marzo por unja escasa mayoría. Pero creo que sería erróneo atribuir la victoria socialista únicamente a la gestión comunicativa del atentado de Madrid y a los acontecimientos posteriores. EI PP había llegado al período electoral con unas encuestas de intención de voto claramente favorable, pero esta diferencia se fue reduciendo de manera de forma paulatina hasta el punto de que el día antes del atentado las dos grandes formaciones PP y PSOE estaban casi empatadas en la intención de voto. Considero que la razón hay que buscarla en los graves errores de la campaña de los conservadores: mientras su candidato a la Presidencia del Gobierno Mariano Rajoy desarrollaba una campaña bien enfocada, con un discurso positivo dirigido a sus públicos para explicar la bonanza económica de los últimos años como base de sus promesas de mejora, José María Aznar hacía y decía cosas distintas. El Presidente del Gobierno saliente pronunciaba diariamente discursos inflamados de nacionalismo, descalificando a sus adversarios de izquierda y en tonos 
amenazadores sobre todo para los catalanes y vascos. El desacierto de esta campaña divergente con dos líneas de discurso contradictorias era doble: de una parte desconcertaba al electorado del PP sometidos diariamente a la disyuntiva de creer al candidato Rajoy o al Presidente Aznar. Pero además Aznar calentaba con sus discursos la campaña de forma que no sólo movilizaba a sus seguidores más radicales sino también a una amplia franja del voto potencialmente socialista de tendencia abstencionista. Rodríguez Zapatero, por su parte, trabajaba de forma sistemática contra una cierta imagen de falta de liderazgo que había conseguido disipar ante la opinión pública. El inexplicable comportamiento del Gobierno en el atentado del 11 de marzo, por tanto, sólo significó el golpe final a una práctica comunicativa del PP, muy equivocada, pero que ya venían practicando a lo largo de la legislatura.

En el texto denominado "El marketing político" (4) Gilles Achache señala tres modelos diferentes de comunicación política a los cuales denomina dialógico, propagandista y de comercialización. Este último, que es el que actualmente domina en todo el mundo, está sometido absolutamente a las reglas establecidas por un marketing político que se ha constituido como técnica autónoma, extrapolando a su terreno sistemas de trabajo del marketing comercial. El modelo dialógico que está dotado de una gran legitimidad por sus raíces en la historia, se basa en un diálogo de doble sentido en el que los diversos actores sociales consideran el intercambio racional de mensajes como la forma más legítima de comunicación política. Finalmente, el modelo propagandístico, según Achache, distingue los actores por sus papeles que no son reversibles ni intercambiables; unos siempre hablan y otros siempre escuchan. El emisor es el ser selecto, aquel cuyo discurso es legítimo por el hecho de que su persona está ungida por las fuerzas que animan los grandes relatos. Al receptor se le intenta impactar no en su razón sino en sus emociones.

Durante la legislatura que se extendió entre los años 2000 y 2004 los procesos de comunicación política impulsados por el Gobierno Español y por el PP de José María Aznar, que contaba con mayoría absoluta en el Congreso de 
Diputados, abandonaron el modelo basado en el marketing político para pasarse al que Achache denomina modelo propagandístico. Los comportamientos de los portavoces gubernamentales y del propio José María Aznar en momentos de crisis como la marea negra provocada por el "Prestige" o la entrada en guerra contra Irak sin siquiera presentar la cuestión al Parlamento, son dos de los hechos más significativos de una actitud habitual que iba acompañada de descalificaciones i amenazas para quien no pesara igual que ellos. Algunos de los momentos más significativos de este período fueron la foto de Aznar en el rancho de Bush con los pies encima de la mesa, o la famosa fotografía de las Azores con el presidente norteamericano y con Blair en la que se certificaba el abandono de la política internacional europeísta y pro árabe de España y su paso al atlantismo. Esta actitud del Partido Popular caracterizada por una comunicación propagandística y unidireccional se prolongó durante la primera legislatura del gobierno Zapatero, pero inició un notable giro cuando Rajoy pudo consolidar su liderazgo en el partido y sobre todo a partir de la irrupción de la crisis económica en la que aparece un Rajoy más distanciado de las posiciones aznaristas. A partir de aquel momento, el nuevo líder del PP aplica de nuevo una estrategia comunicativa basada en el marketing político -en la que se abandona la línea agresiva y radical - para volver a enlazar con la evolución que ha ido marcando la comunicación política en la España de la transición, adoptando unos planteamientos y unas formas de actuación homologables con las de los países líderes de la Unión Europea.

\section{Marco legal y político de la Transición}

La transición política en España, al pasar de una dictadura sanguinaria a una democracia sin que se produjera una ruptura clara ha despertado un fuerte interés entre los politólogos.

Al analizar esta transición algunas tesis ponen el acento en el nivel de desarrollo y modernización al que había llegado el país al entrar en la recta final del siglo XX. Linz se acerca más a lo que sucedió al señalar el papel 
determinantes que siempre tienen las elites políticas en la construcción de alternativas. Siguiendo esta tesis Cayo Sastre ha estudiado el fenómeno español para concluir que, independientemente de las dificultades que podía contener el mantenimiento de un régimen autoritario en España en medio de una Europa democrática, efectivamente, la transición en España fue el resultado de un pacto entre elites. (5) Pero el factor innovador que aporta Sastre en uno de sus trabajos es que los actores del pacto tuvieron un amplio margen de negociación gracias a la existencia de una sociedad políticamente desmovilizada. La mayoría de manifestaciones de masa registrados en España entre 1975 y 1978, año en que fue aprobada la Constitución, tuvieron como objeto la reivindicación de cuestiones sociales, educativas y relativas al bienestar de las personas. La petición de amnistía para los presos fue la que provocó las movilizaciones más numerosas estrictamente políticas. Pero no hay registrada, por ejemplo, ninguna manifestación en la que se pidiera la República o la depuración de responsabilidades de quienes colaboraron con la dictadura.

En este contexto político las nuevas instituciones de la democracia diseñaron el marco legal en el que actualmente se desarrollan las campañas electorales, una buena parte del cual está destinado a regular el uso de la publicidad política durante estos períodos.

Hay tres textos fundamentales: el primero es la Ley de Reforma Política de 1976 que establece las bases y establece las decisiones clave para la transición del sistema autoritario al democrático. El decreto 20/1977 publicada el 18 de marzo de 1977, tres meses antes de las primeras elecciones democráticas del 15 de junio, contiene las normas que regularán los comicios.(6) Siete años más tarde, durante el primer gobierno de Felipe González fue aprobaba la LORE, "Ley Orgánica del Régimen Electoral General". Esta ley confirma las principales decisiones del decreto de 1977 y las desarrolla sobre todo en aquellos aspectos que se refieren a la comunicación y más en concreto, a la concesión de espacios gratuitos en las emisoras públicas de radio y televisión a los partidos y coaliciones. (7) 
El Congreso de los Diputados y el Senado Español, al desarrollar la normativa electoral de la nueva democracia priorizaron sobre todo tres aspectos:

1. Existencia de partidos fuertes. Los partidos políticos, habían sido junto con la masonería, el comunismo y los territorios con reivindicaciones independentistas, los cuatro enemigos recurrentes de la propaganda política interna del franquismo. Por esta razón se optó por las listas cerradas y bloqueadas que otorga gran fuerza y mucho protagonismo a los aparatos de los partidos y también al político que encabeza las listas.

2. Facilitar la creación de mayorías. Los problemas de gobernabilidad que sufrió la Segunda República a causa del sistema proporcional, ejercieron un importante peso sobre los constituyentes. Esto les llevó a optar por la aplicación de la regla d'Hont para determinar el reparto de escaños a partir del voto obtenido por los partidos. Se trataba de primar de manera significativa a aquellos partidos que lograban más votos en detrimento de los que obtenían menos.

3. Evitar la excesiva fragmentación del Congreso. Para conseguir este objetivo se acordó que las listas que no consiguieran como mínimo el $3 \%$ quedaran eliminadas en el reparto de escaños.

Por lo que hace referencia a la comunicación y sobre todo, a la utilización de medios públicos se recurrió a la doctrina de la proporcionalidad, aplicada por primera vez por la BBC británica, que otorga tiempo de antena en los medios públicos en proporción al número de votantes y diputados de cada partido y es aplicada en muchos países europeos. Para evitar una excesiva extensión de los aspectos regulatorios resumimos este cuerpo de doctrina en los siguientes puntos:

1. Se garantiza el derecho a espacios gratuitos de propaganda electoral en las emisoras de radio y televisión de titularidad pública a los partidos y coaliciones que concurran a los comicios. Esto afecta no solo a la primera y 
a la segunda cadena de Televisión Española sino a todas las televisiones públicas que conforman el tercer canal.

2. El tiempo destinado a propaganda gratuita, una vez fijado por la Junta Electoral, se distribuye de forma proporcional, tal como hemos señalado, entre los partidos y las coaliciones en base al número de votos obtenidos en las anteriores elecciones. Los partidos que obtuvieron más votos tienen prioridad para escoger los momentos de mayor audiencia.

3. La Ley prevé que los partidos y coaliciones que no concurrieron a los anteriores comicios o bien concurrieron pero no obtuvieron ningún escaño, puedan utilizar diez minutos en los medios públicos.

4. Para poder acceder a la radio y a la televisión de forma gratuita los partidos y la coaliciones han de presentar lista como mínimo en el $75 \%$ de las circunscripciones electorales aunque la ley prevé una excepción para los partidos que hayan obtenido buenos resultados en una comunidad concreta, con lo que se salva la presencia en antena de los principales partidos nacionalistas Euskadi, Galicia y Catalunya.-

5. Está prohibida la contratación de espacios de propaganda en las televisiones privadas y en la radio y la televisión públicas.

6. Las televisiones locales propiedad de los ayuntamientos, cuando se celebran elecciones en el municipio ofrecen espacios gratuitos con misma regla que estable la proporcionalidad.

7. Los políticos sólo pueden pedir el voto durante los quince días de campaña electoral. Por radio y televisión la petición de voto está prohibida durante las semanas anteriores a la campaña oficial.

8. Nadie, ni la Junta Electoral Central, ni la Comisión de Radio y Televisión que emana de la Junta, ejercen ningún tipo de tutela previa sobre los contenidos, ni supervisan los spots. 
Hay que decir que el Estado sufraga a cada partido o coalición el envío de un mailing a todos los votantes en el que cada lista puede incluir propaganda y una papeleta de votación.

\section{Nuevas técnicas y nuevas estrategias}

Dentro del marco legal que hemos descrito, la comunicación política en democracia inició su andadura en 1977. En un primer momento, partidos y comunicadores sabían muy poco de cuestiones tan significativas en el ámbito del marketing como segmentación de públicos, investigación del universo electoral o personalización de la campaña. Pero estos déficits técnicos se han corregido hasta llegar a la situación actual en la que las campañas y la comunicación de partidos e instituciones de gobierno han conseguido un nivel de madurez en el que nada se deja al azar. Aunque todavía quedan pequeños partidos o gobiernos de municipio pequeños que comunican con formas arcaicas, esto ya no es lo normal. Los programas se dan a conocer después de haberlos contrastado con lo que piensan y desean los votantes. Los cabezas de lista y los candidatos que la componen actúan de forma coordinada y mensajes y discursos se modulan según las expectativas del público receptor, tal como establece el marketing político.

Algunos autores denominan "americanización" a la incorporación de estas nuevas técnicas. Pero a pesar del éxito que ha obtenido este término, no parece que pueda calificar con propiedad la modernización que ha sufrido en la segundad mitad del siglo XX la comunicación política, no sólo en Norteamérica, sino también en la mayoría de países de la Unión Europea. (8). La modernización a la que nos referimos consiste en la extrapolación de técnicas utilizadas en el marketing comercial a la comunicación política y es cierto que en muchos casos esta transposición se hizo en los Estados Unidos. Pero ni todas las novedades en el campo de la comunicación estratégica política vienen del campo comercial, ni todas ellas han estado utilizadas en Norteamérica por primera vez. Por el contrario, algunas técnicas como la 
repetición, la simplificación o la orquestación, por poner algunos ejemplos, habían sido utilizadas repetitivamente por la propaganda política desde tiempos antiguos, antes de convertirse en técnicas publicitarias.

El rasgo que mejor define a las campañas políticas españolas es que están fuertemente centradas en los medios, los cuales, en muchos aspectos han sustituido a escenarios clásicos de la comunicación política, como el propio Parlamento. Los medios constituyen el territorio en el que los políticos se dan a conocer. Es donde, con sus acciones y sus declaraciones, reposicionan su imagen en función de los objetivos que quieren obtener. Los medios son el escenario en el que se desarrolla el drama diario de la política, las peleas, las críticas, la fijación de posiciones y la respuesta de los ciudadanos a este drama continuado de la que son reflejo las encuestas. (9)

Dentro del escenario de la comunicación política encontramos tres tipos de actores principales: los políticos, los partidos y los propios medios de comunicación. Vamos a analizar del papel en cada uno de ellos en la comunicación política que se ha desarrollado en España en los últimos años.

Durante el período de Felipe González que como es sabido fue presidente del Gobierno hasta finales de 1996 los socialistas desarrollaron una eficiente cultura de autoaprendizaje bajo el impulso del entonces vicesecretario del PSOE Alfonso Guerra. El partido se apoyo en profesores universitarios que militaban en la formación para introducirse en la elaboración y utilización de encuestas electorales. Para la creatividad de la campaña se utilizó a expertos de la agencia publicitaria "Contrapunto" que más adelante crearon su propia agencia "El Viso" la cual trabajó básicamente para socialistas. Guerra coordinaba desde la vicepresidencia del PSOE todas las campañas generales y dirigía la movilización. En la escuela Jaime Vera, creada para la formación de cuadros siempre se han desarrollado programas de comunicación, de construcción de imagen y de relaciones con los medios. Durante toda esta época se fue produciendo un acercamiento progresivo entre los dirigentes del PSOE y los responsables de PRISA, el grupo editor de "El País", propietario de 
Canal Plus y Digital Plus y también se la SER, la primera cadena de radio española. La desaparición de Alfonso Guerra de la vicesecretaría general del PSOE significó un paréntesis ineficiente, que se pagó en las elecciones del 2000 en que Joaquín Almunia protagonizó una campaña dispersa y de poca calidad. Posteriormente, Rodríguez Zapatero asignó las tareas comunicativas a expertos en Relaciones Públicas que al principio buscaron colaboración externa en creativos publicitarios que habían trabajado para el Partit de los Socialistes de Catalunya. En el ámbito de la organización socialista, el PSC siempre ha gozado de una amplia autonomía en lo referente a comunicación.

Se ha sugerido que el último candidato a la Presidencia del Gobierno y actual Secretario General Alfredo Pérez Rubalcaba tiene una fe limitada en las estrategias de comunicación política. Mientras Mariano Rajoy acudió al debate televisivo de las elecciones acompañado de un sociólogo, un responsable de prensa y el experto en telegenia del PP Jorge Rábago, no parece que Rubalcaba tuviera bien cubierto este aspecto tan importante en una confrontación televisiva. Una vez secretario general ha seguido con la tradición de los gobiernos PSOE de nombrar responsables de comunicación a periodistas del grupo Prisa. En el presente caso, Rodolfo Irago antiguo responsable de informativos de la SER ha sido contratado como director de comunicación del PSOE. Otra periodista que había trabajado en la SER, Eva Cuesta se ha hecho cargo de la Oficina de Prensa del grupo parlamentario socialista en el Congreso.

La mejor campaña realizada por el PSOE fue la de 1982. Sus inspiradores y creativos supieron captar que el pueblo español, incluida la mayoría silenciosa, estaba preparada para enterrar el franquismo. Las fuerzas democráticas habían conseguido superar el intento de golpe de estado del 23 de febrero de 1981 y el PSOE había renunciado a su programa histórico de orientación marxista, para intentar captar a los electores de centro. Esto le permitió personalizar en Felipe González los deseos de entrar en una nueva época. "Por el cambio" fue el afortunado eslogan que supo interpretar y resumir en tres palabras aquello por lo que la gente iría a votar en aquella ocasión. Los 
discursos de todos los candidatos socialistas convergieron en aquella frase resumen, potenciada por la figura joven y televisiva de González, un político con gran capacidad oratoria. (10)

El Partido Popular no incorporó el marketing político en sus estrategias hasta el nombramiento de José María Aznar como candidato a la Presidencia del Gobierno el año 1989. Hasta entonces el PP contaba únicamente con una oficina de prensa desde donde se distribuían comunicados sin ninguna cultura de construcción de imagen. Cuando había que elaborar campañas electorales, el PP las encargaba a una agencia de Publicidad que de forma coordinada con la dirección del partido se responsabilizaba de su elaboración en todos los aspectos técnios. Con Aznar llegó el sociólogo Pedro Arriola que hasta hoy viene siendo responsable de los estudios demoscópicos electorales y de su explotación. En base a algunos periodistas como Miguel Ángel Rodríguez y algún político interesado en las cuestiones comunicativas, el PP inició una larga marcha de aprendizaje que, desde un punto de partida arcaico lo situó en una posición avanzada en lo referente a comunicación estratégica. Aznar importó además de Castilla-León, territorio del que había sido Presidente una técnica comunicativa relativamente simple que consistía en gobernar con el soporte incondicional de unos cuantos grupos multimedia, que eran atraídos utilizando las posibilidades que comporta el poder. Este mismo modelo es el que aplicó cuando estuvo al frente del gobierno español con la creación del grupo Telefónica, que hoy ha perdido relevancia como grupo informativo multimedia, pero que en aquel momento se intentó utilizar desde el Gobierno como alternativa al grupo Prisa.

La mejor campaña del Partido Popular fue la de las elecciones del 2000. José María Aznar fue el ganador y como hemos relatado consiguió la mayoría absoluta, lo que le permitió gobernar sin la necesidad de apoyos de nacionalistas catalanes y vascos que habían sido sus aliados parlamentarios en la anterior legislatura. La campaña la personalizó el PP en el líder José María Aznar y presentó las mejoras conseguidas en los anteriores cuatro años en materia de reducción del paro, creación de nuevas infraestructuras y 
avances en la equiparación de género en el ámbito laboral como un paradigma de lo que el Gobierno del Partido Popular llevaría a cabo la siguiente legislatura. La bajada de algunos impuestos también fue presentada como una mejora. El slogan único de la campaña lo constituyó la frase "Vamos a más" que transmitía de forma muy efectiva la capacidad de superar por parte del PP las realizaciones de los primeros cuatro años. (12)

\section{Medios polarizados y otros actores del proceso electoral}

La actual comunicación política en España no se puede entender sin el hecho de que una buena parte de los grupos multimedia están divididos en dos bloques fuertemente enfrentados en función de cuál sea el partido al que dan su apoyo. Al lado del PSOE, como ya hemos señalado, se alinea sobre todo el grupo PRISA. La buena relación entre los gobiernos de signo socialista y este grupo multimedia se volvió a visualizar durante el período Zapatero al otorgarles este una nueva cadena de televisión generalista -la Cuatroaprovechando los cambios en el sistema de televisión motivados por el paso a la digitalización. La afinidad entre la cadena y los socialistas se evidencia no sólo en los habituales contenidos de los medios del grupo sino también en el hecho de que cuando gobiernan los socialistas la mayoría de los responsables de prensa de los diversos ministerios son escogidos entre los profesionales de PRISA. Alfredo Pérez Rubalcaba ha confirmado esta práctica al nombrar antiguos periodistas de Prisa en su equipo.

Los medios que dan soporte al PP ya sea en situaciones de gobierno ya sea cuando está en la oposición son sobre todo el diario El Mundo, el segundo diario de más tirada en Madrid y los diarios ABC y El Imparcial, también de la capital. En el ámbito radiofónico la cadena Cope, la mayoría de cuyas acciones está en manos de los obispos, defiende las posiciones más extremistas del PP sin evitar menosprecio y descalificaciones a los oponentes. Recientemente ha conseguido una cierta relevancia el grupo multimedia Intereconomía que cuenta con un canal de televisión, una emisora de radio y un diario en Madrid 
distribuido por toda España; La Gaceta. Para estos medios, el periodismo es una práctica puramente instrumental ya que todos ellos han sido concebidos al estilo de la Fox o las emisoras que sindican el programa de Rush Limbaugch en los Estados Unidos- como puntas de lanza de una operación política ultraconservadora y centralista. Aparte de los medios citados, la opción conservadora militante cuenta con un grupo de comentaristas políticos muy activos que se caracterizan por su aversión a los socialistas. Este grupo, actualmente más disperso, encontró un buen motivo de cohesión entre los años 1990 y 1996 cuando el gobierno de Felipe Gonzales se vio involucrado en el caso FILESA en el que se investigó y condenó a dirigentes del partido por financiación ilegal del mismo. $Y$ además el caso GAL, que vinculaba a dirigentes socialistas con un grupo secreto involucrado en la guerra sucia contra ETA. La alianza entre los grupos mediáticos adversos al PSOE, los periodistas citados y el PP les llevó a fijar como objetico la desaparición del poder de Felipe González para lo cual adoptaron incluso un slogan difundido de forma repetitiva que se hizo famosos entre la opinión pública española: "Váyase señor González"

Las controversias entre pro socialistas i contrarios se siguen reflejando cada día en los contenidos de televisión, radio, prensa e Internet, aunque en el bando conservador puede distinguirse a un grupo de medios que acusan al actual presidente Mariano Rajoy de blandura frente al adversario señalándole como referencia las posiciones defendidas por el ex presidente José María Aznar. Al margen de este sesgo los medios juegan un rol en la comunicación política homologable al que desarrollan en los países europeos, con algunas peculiaridades:

Los debates electorales televisados entre los candidatos más importantes, sólo en tiempos recientes se han incorporado como una tradición en el corto recorrido democrático español. En 1996 José María Aznar que iba empatado con su oponente en la intención de voto consiguió que Felipe González accediera a participar en dos debates durante la campaña electoral que les enfrentó. Estudios posteriores demostraron que José María Aznar ganó el 
primer debate. Pero esta victoria fue contrarrestada por Felipe González, que al imponerse por un amplio margen en el segundo, también ganó las elecciones.

José María Aznar no concedió debates televisivos a las elecciones generales del año 2000 y tampoco se celebraron debates en el 2004 con lo que pareció reforzarse la tendencia a que estas confrontaciones televisivas fueran a tener poca presencia en las campañas electorales. Esta situación era criticada por algunos autores que lo atribuían a un marco legislativo deficiente. (13) Pero la situación cambió de signo en las elecciones de 2008 que enfrentaron a Zapatero y Rajoy. La Academia de las Ciencias y las Artes de Televisión invitó a debatir ante las cámaras a los dos candidatos y ambos no juzgaron oportuno negarse. La Academia organizó dos debates en los locales de la Feria de Madrid que retransmitieron diversas cadenas las cuales pagaban de forma prorrateada los gastos que generaba el acontecimiento. El share obtenido fue cercano al sesenta por ciento Para las elecciones de 2012 la Academia volvió a convocar a los dos candidatos de los partidos mayoritarios Esta vez aceptaron un único debate cuya señal producida también por la propia academia fue sufragada nuevamente por las televisiones que decidieron retransmitirlo. Es muy probable que estemos en camino de que, al igual que sucede en países como Francia o Estados Unidos los debates televisivos, con la Academia de la Televisión como organizadora se consoliden como una tradición inevitable para cualquier candidato a la Presidencia del Gobierno. Cabe señalar finalmente que el hecho de que estos debates no se celebren en televisiones públicas permite que, sin ningún forcejeo legal, se puedan celebrar con la única participación de los candidatos de las dos fuerzas mayoritarias, lo cual es evidente que contribuye en alguna medida a impulsar el bipartidismo.

Conjuntamente con los debates y los bloques informativos incrustados en los telenoticias, los spots constituyen el centro de la campaña electoral en televisión. Pero su duración se ha ido recortando a lo largo de los años. De los diez minutos que duraban en las primeras elecciones de la transición democrática se ha pasado a los cuatro minutos el día en que se abre la 
campaña y a los 30 segundos otros días. Su elaboración participa de la dramatización, de la búsqueda de espectáculo y de la personalización que afecta a toda la producción televisiva. Desde 1996 cada campaña contiene algunos ejemplos de publicidad negativa aunque su cantidad no iguale ni de lejos el porcentaje que registramos en las campañas norteamericanas lugar en el que tuvieron su origen este tipo de contenidos.

La radiodifusión es el medio que representa una mayor especificidad ya que en España las emisoras de radio privadas pueden vender espacios publicitarios electorales, con la única salvedad de que el precio del tiempo no sea más caro que el que facturan los radiodifusores a sus clientes comerciales. Esta normativa hay que entenderla como consecuencia de la historia divergente que ha tenido la radiodifusión española respecto a la europea. En la década de 1920, cuando los mayores países europeos pasaron su radiodifusión al sector público con el objetivo de potenciarla, la dictadura de Primo de Rivera no consiguió imponerse a los empresarios españoles de la incipiente radiodifusión. España no tuvo radio pública hasta 1940 con la creación de Radio Nacional, que ejerció el monopolio informativo durante la dictadura, pero que siempre ha compartido las ondas con emisoras pertenecientes a grupos privados.

La prensa escrita española durante las campañas electorales adopta unas rutinas de trabajo que la llevan a presentar la campaña electoral al estilo "carrera de caballos". Las encuestas son presentadas por los diarios rodeadas de un cierto halo de magia. Su contenido se titula en forma de predicción y muchas veces saltándose las reglas que impone la estadística. Los grandes diarios buscan sinergias con institutos de opinión. Cada gran rotativo tiene una empresa de sondeos preferida que hace sus trabajos a precio reducido a cambio de publicidad.

La otra rutina dominante en la prensa escrita es la búsqueda de confrontación entre políticos. Esto lleva a que los periodistas intenten que los políticos se aludan y se contesten los unos a los otros configurando de forma repetitiva lo que se ha denominado "periodismo de declaraciones" Pero el margen de 
actuación de los periodistas supera muy poco lo que marcan los partidos. Como afirma Teresa Sádaba: "La agenda de los diarios es más cercana a los partidos que a los ciudadanos" (14) y es dudoso que este sea el mejor camino para que los electores se puedan informar sobre los contenidos de los programas.

La primera vinculación de Internet a la campaña electoral se produce en la campaña del año 2000 y es en las siguientes elecciones generales- en 2004cuando su uso se hace generalizado.(15) Actualmente Internet, con la incorporación de las redes sociales, se ha convertido en uno de los más importantes instrumentos de campaña aunque en ningún caso ha sustituido ni sobrepasado en importancia a los medios tradicionales de comunicación y movilización .Internet se utiliza sobre todo para difundir contenidos programáticos, la agenda de actos de la campaña y declaraciones de los líderes. Las redes sociales han incorporado a gente antes alejada del debate político y de hecho los partidos intentan conectar por medio del 2.0 sobre todo con los públicos jóvenes. En algunas elecciones los candidatos usuarios de Twitter han superado el 80 por ciento. Pero el nivel de interactividad sigue siendo reducido aunque el tráfico aumenta durante los periodos electorales. No se acostumbra a reclutar y a organizar voluntarios, y apenas se utiliza la red para recaudar dinero como sucede en Norteamérica; sólo se encuentran opiniones de candidatos y respuestas de los líderes a las preguntas que les formulan los internautas. Las novedades más recientes se concentran en la creación de algunos espacios intranet para la relación de los partidos con los militantes, la creación de webs especiales para los cabezas de lista junto a la del partido y la aparición de blogs firmados por candidatos y políticos en activo así como la incorporación de elementos audiovisuales en la página web. Las páginas también acostumbran a ofrecer merchandising como un instrumento complementario para promocionar partidos y candidatos.

Además de los ya citados, en los procesos electorales españoles aparecen otros actores, algunos con una larga tradición intervencionista como la jerarquía eclesiástica. Bastantes obispos, en todas las campañas emiten su 
opinión a favor de las posiciones conservadoras. Los bancos, cuando se acerca la campaña electoral se ponen de acuerdo discretamente, para adjudicarse de forma compartida la concesión de créditos a los partidos que en algunos casos, nunca serán retornados, lo cual les concede un importante poder oculto sobre todo el sistema.(16) También debemos referirnos a los profesionales expertos en comunicación que no acaban de lograr un status propio en el sector político. Y finalmente están los grupos de presión y los lobbys, la mayoría representando intereses específicos. Junto a ellos aparecen también los lobbys ciudadanos como los foros sociales, los movimientos antiglobalización o los que forman el 15-M algunos de los cuales, no todos, muestran sus preferencias por alguna candidatura días antes de la votación.

Un sector en el que la comunicación también ha crecido y se ha perfeccionado de manera notable desde 1976 es el de la comunicación gubernamental tanto en el ámbito autonómico como en el local. Casi todos los ayuntamientos de más de 5000 habitantes tienen una oficina de comunicación. I aunque la crisis ha llevado a recortes en el ámbito comunicativo, hoy casi todos los municipios tienen página web oficial y casi todos cuentan con instrumentos propios para poder informar directamente a sus públicos. Con ello rebajan su dependencia de los medios de comunicación.

El instrumento más habitual para difundir la gestión de gobierno es el boletín municipal que también recoge opiniones de los representantes elegidos y sus grupos municipales sobre los problemas de la localidad. Aparte de los instrumentos citados, muchos ayuntamientos patrocinan y financian radios y televisiones públicas. Son también cada vez más habituales las Oficinas de Atención al Ciudadano desde las que se informa de los procedimientos del ayuntamiento a las personas interesadas.

Diversas universidades ofrecen formación de postgrado en comunicación pública a periodistas que trabajan en los gobiernos. Esto ha provocado mejoras importantes en el planteamiento que tienen de su trabajo. Antes de dedicaban sobre todo a difundir información indiscriminada a los medios de comunicación 
y a poner en relación de periodistas y políticos mientras que actualmente, una buena parte de comunicadores políticos se consideran responsables de elaborar y aplicar el Plan de Comunicación entendido como un instrumento más de gobierno.

\section{Debates y propuestas para mejorar la calidad de la democracia}

Uno de los elementos más preocupantes del sistema democrático español es la mala imagen de la política y de los políticos entre amplias capas de la opinión pública que, sobre todo entre los jóvenes, induce a la abstención

En el marco del debate permanente que intenta aportar ideas para mejorar esta situación hay tres propuestas que saltan a la actualidad de forma intermitente cada vez que los medios se hacen eco de un escándalo o de una irregularidad que involucra a políticos. La limitación de las donaciones a los partidos y la transparencia en la adjudicación de obras y servicios por parte de los gobiernos es la cuestión más recurrente. Una nueva ley de financiación aprobada en el año 2007 (8/2007) obliga a que el nombre de los donantes a los partidos sea público, pero eleva las posibles donaciones a 100.000 euros anuales tanto para personas físicas como jurídicas. En el caso de las fundaciones vinculadas a los partidos, los límites de las donaciones están establecidos en 150.000 euros. El Tribunal de Cuentas, cuyos informes son públicos y pueden leerse en su web afirmaba al entregar sus dictámenes sobre las cuentas de los partidos del año 2006 que ninguna de las formaciones analizadas, 17 de ellas presentes en el Congreso y 14 en los parlamentos autonómicos cumplían con lo estipulado por la ley. El Tribunal se queja de que faltan datos de ingresos y salidas sobre todo de las sedes locales y tampoco están claras las subvenciones de los parlamentos autonómicos y de los ayuntamientos que en 2006 sumaron 123 millones de euros.

La segunda propuesta se refiere a la posibilidad de pasar de las actuales listas cerradas y bloqueadas a listas abiertas que otorguen a los electores un mayor 
margen de decisión. Dentro del mismo intento de dar un mayor protagonismo a la sociedad y restarlo a los aparatos de los partidos, otra iniciativa pide la introducción de elecciones primarias en el seno de las organizaciones políticas a fin de que militantes y simpatizantes puedan intervenir en la elección de sus candidatos. Esta propuesta fue aceptada por el PSOE en 1998 y ha sido ratificada por el último congreso del partido celebrado en Sevilla este mismo año. Esto parece haber satisfecho a las bases socialistas ya que sin duda implica un avance en la democratización interna de la organización. El sistema de primarias que aprobó el PSOE en 1998 empezó jugando un papel movilizador entre los candidatos socialistas a las alcaldías. Pero el partido entró en shock cuando en el año 2000 en las primarias para elegir candidato a las elecciones generales, el antiguo ministro de Obras Públicas Josep Borrell ganó al entonces Primer Secretario de partido Joaquín Almunia y quedó proclamado para encabezar la lista por Madrid. Meses después, Borrell renunció a su candidatura y Almunia se presentó contra José María Aznar, pero las jerarquías socialistas habían interiorizado que, por más que las bases del partido siguieran exigiendo primarias, el sistema necesitaba una revisión de la normativa que de hecho quedó en suspenso. La cuestión ha dado un giro importante en el 38 Congreso celebrado el 3 de febrero de 2012 en Sevilla. En él, como ya hemos explicado, los Socialistas volvieron a aprobar, a inspiración de lo que hicieron sus homólogos franceses, la celebración de primarias para elegir al candidato socialista a la presidencia del gobierno en las que podrán votar no sólo de los militantes, sino también de los simpatizantes del partido.

En lo que se refiere a la regulación de la comunicación durante el período electoral, las cuestiones que generan mayor discrepancia son la prohibición de que las cadenas privadas de televisión puedan contratar espacios con partidos y candidatos y obligación de la proporcionalidad en los noticiarios electorales incluidos dentro de los telediarios. Los periodistas de la televisión pública de Catalunya, TV3, han encabezado acciones de presión para poder ser ellos los que definan el interés y la valoración de las noticias electorales teniendo en cuenta las fuerza de cada candidatura sólo de manera global. Esta 
reivindicación, que afecta a los informativos, pero no a los espacios gratuitos de propaganda, ha sido asumida por el Colegio de Periodistas de Catalunya. La Federación de Asociaciones de la Prensa y el Colegio de Periodistas de Madrid también se han sumado a la propuesta y el Consejo Audiovisual de Catalunya también la ha visto con buenos ojos, pero al menos por el momento, esta movilización de los periodistas no se ha traducido en reformas concretas.(18).Los periodistas también muestran su oposición a que los partidos filmen y editen ellos mismos las imágenes que quieren incluir en los bloques informativos electorales, así como a las denominadas ruedas de prensa sin preguntas. Sobre el otro debate referente a la posibilidad de contratar publicidad en las televisiones privadas, cabe señalar que se trata de un tema recurrente que a veces es defendido por autores que, de forma contradictoria, al mismo tiempo piden una mayor austeridad en los gastos electorales de los partidos (19). La prohibición de contratar espacios electorales de propaganda en las TV privadas es una regla de prudencia para evitar que los partidos entren en una espiral de gastos que los podría llevar a adquirir deudas y a impulsar prácticas recaudatorias que únicamente aportarían nuevos problemas.

\section{Las dos almas del Partido Popular}

Esta mirada sobre la comunicación política en España no sería completa sin relatar la neutralización del ala más dura del PP que ha significado el acceso al poder de Mariano Rajoy. Entre 2003 y 2010 mientras José María Aznar controlaba el partido, incluso tras el nombramiento de Mariano Rajoy como candidato a la Presidencia del Gobierno y más adelante líder del PP, los populares intentaron un cambio en las estrategias clásicas de propaganda electoral que intentan siempre mejorar el posicionamiento del líder acercándolo a una masa crítica de votantes para que le otorguen la victoria. Esto último es lo que prescribe el marqueting político y es lo que había hecho el propio Aznar reivindicando para el PP el espacio de centro y citando a Azaña 
como uno de sus guías, en su larga marcha hacia la presidencia del Gobierno español.

Pero esta línea de reposicionamiento hacia el centro no fue nada fácil de aplicar por parte de Mariano Rajoy ya que mientras él se presentaba con unas posiciones moderadas para atraerse votantes indecisos, el PP, con muchos cuadros de la época Aznar aún en la cúpula del partido, adoptaba una línea superagresiva y descalificadora de todo lo que no fueran ellos mismos. Todo ello impulsado ideológicamente por FAES un think tank dotado de gran dinamismo y recursos económicos presidido por el propio Aznar que no esconde sus lazos con organismos homólogos de Estados Unidos. Inicialmente las conexiones norteamericanas de FAES se concentraban en Cato's Institute, financiado por Ruperth Murdoch y con vinculaciones con el Tea Party, que se caracteriza por su aversión al sector público y a toda forma de intervención estatal. Más adelante FAES priorizó su relación con American Enterprise el think tank más cercano al presidente Bush entre cuyos miembros se encuentran los inspiradores de la invasión del Irak Paul Wolfowitz y Richard Perle.

Una hipótesis que explicaría la estrategia rompedora adoptada por el ala derecha del PP sería que con su discurso buscan una transformación en profundidad de la visión del mundo que tiene el electorado español, relativamente progresista en cuestión de costumbres y autoposicionado políticamente en el centroizquierda.

Esto se intenta promocionar desde FAES mediante un trabajo sistemático de "framing" que tal como explica George Lakoff (20) intenta introducir nuevas ideas marco nuevas estructuras conceptuales que condicionen los mecanismos del pensamiento. Esto es lo que han conseguido hacer en Norteamérica los think tanks conservadores conjuntamente con otras fuerzas del entorno del Partido Republicano penetrando en el espacio electoral de los demócratas que desde 1980 sólo habían conseguido una presidencia gracias al carisma personal de Bill Clinton. Este fue sucedido por el republicano Bush, que a pesar 
de haber sido considerado como una de los peores presidentes de los que ha tenido Norteamérica logró la reelección, aunque su mala gestión acabó por arruinar toda posibilidad de sucesión republicana abriendo paso a Obama.

Los valores que impulsan los dirigentes del Partido Popular que impulsan FAES en este intento de derechizar la sociedad son "la salvación de la familia tradicional", la "patria unida" y" la vida desde el mismo momento de la concepción" según sus propias palabras, además de la prevención ante los inmigrantes, la libertad total de los mercados y como la limitación del sector público.

Tras José María Aznar y su estrepitosa gestión de los atentados del 11M los socialistas con Rodríguez Zapatero al frente ocuparon la presidencia del Gobierno durante dos legislaturas. El estilo comunicativo de Rodríguez Zapatero se basó de nuevo en la vía del marqueting que sin duda contribuyó al éxito inicial con la primera elección, pero que posteriormente cayó en exageraciones y malas decisiones que suplantaron a la propia política y le alejaron de los problemas reales. Todo ello bajo el fuego de una oposición durísima del Partido Popular que, sobre todo en sus primeros cuatro años acusaba al líder del PSOE de "mentiroso", "dictador", "indecente" "ridículo" ,"cobarde", "acomplejado" y "fracasado" entre otros epítetos (21) A medida que avanzaba la segunda legislatura Rodríguez Zapatero perdió por el camino todo el bagaje ideológico del socialismo tradicional al intentar atajar la crisis económica y al igual que habían comenzado a hacer Irlanda y Portugal, Papandreu en Grecia y más tarde Monti en Italia, fue tomando las decisiones que marcaban los mercados y la troika formada por la Comisión Europea, el FMI y el BCE.

Con la victoria del 20-N del 2012 el Partido Popular regresa al poder tras una campaña muy bien elaboraba que ante el cambio inevitable que imponían las graves contradicciones políticas de Zapatero, invitaba al electorado a sumarse a su victoria electoral ("Súmate al cambio"). El paso del tiempo aclarará lo que a día de hoy, suponen las dos grandes incógnitas de futuro. La primera, 
económica, deja en el aire la pregunta de si España evitará la intervención de su economía y la segunda, que afecta a la comunicación, apunta a si las posiciones representadas por Rajoy más en línea con el conservadurismo tradicional lograrán poner freno a las ansias radicales de Aznar, FAES y el ala derechista del PP más cercanas a lo que sería el "Tea Party" norteamericano. Si así sucediera nos encontraríamos con dos estrategias de comunicación la del PSOE y la del PP técnicamente opuestas e ideológicamente polarizadas con graves dificultades para lograr pactos de gran alcance entre fuerzas políticas.

\section{NOTAS}

1. En la crónica de Le Monde del 14/3/06, publicada en motivo de los dos años de victoria del PSOE se puede leer: "Les reformes votées ou en cours d'examen sont, pour la plupart, violemment combattues pour une opposition qui, sous la houlette de Mariano Rajoy, président de Parti Populaire (PP), n'a ni compris ni accepté sa défaite. L'atmosphère politique est si détériorée que le débat se résume, certains jours, en un pur et simple échange d'insultes".

2. Para una más amplia información sobre la comunicación en el 11-M. Ver: Pozas, V.S.; Toral,G. "La gestión de la comunicación institucional entre el 11 y el 14 M". En Revista ZER, número 17. Bilbao : Facultad de Ciencias Sociales y de la Comunicación. Y en : Arceo Vacas, José Luís "El modelo de comunicación del PP". En Revista Análisis no 32, p. 15-34. Barcelona: Departamento de Periodismo de la Universidad Autónoma de Barcelona.

3. En el artículo citado de la Revista Análisis José Luís Arceo Vacas afirma en la página 21: "Parece claro que fue de nuevo la mala gestión política y comunicacional del Gobierno del PP. En este caso, se trataba nada menos que de los atentados del 11 de Marzo de 2004, lo que muy probablemente motivó a votar a diversos segmentos de público, que, hasta este momento tendían a la abstención". Y este público és mayoritariamente próximo al PSOE.

4. Achache, Gilles (1992). "El marketing político" en J.M.Ferry, et al, El nuevo espacio público. Barcelona : Gedisa, pp 112-123.

5. Sastre García, Cayo (1997). "La transición política en España: una sociedad desmovilizada". En REIS, no 80, octubre-diciembre, p. 33-68. Madrid : Centro de investigaciones Sociológicas.

6. Para una descripción más detallada de la normativa vigente en la propaganda electoral en España, ver: Herrero, Julio César; Connolly-Ahren, Colleen (2004). "Origen y evolución de la propaganda política en la España democrática : "Análisis de las técnicas de los mensajes en las elecciones generales del año 2000". En Doxa Comunicación no 2, mayo, p. 151-173.

7. La Ley Orgánica del Régimen Electoral General (LOREG) fue votada el 19 de junio de 1985 durante el primer gobierno presidido por Felipe González. Cuenta con 6 títulos y 227 artículos. La LOREG ha sido modificada tres veces por las leyes orgánicas 1/1987 del 2 de abril, 8/1999 del 13 de marzo y 6/1982 del 2 de noviembre. Otras dos leyes orgánicas han completado la normativa vigente en la propaganda: la 2/1988 del 3 de mayo, que prohíbe la compra de espacios publicitarios en las televisiones privadas, y la 14/1995 del 22 de diciembre que la prohíbe en las televisiones locales.

8. Dader, José Luis (1999). "Entre la retórica mediática y la cultura política autónoma : la comunicación política electoral española como encrucijada de la americanización y el pluralismo democrático tradicional". En Cuadernos de la Información y Comunicación, № 4. Madrid: Facultad de Ciencias de la Comunicación. Universidad Complutense, 1999.

9. Para Dominique Wolton la comunicación política es "el espacio en que se intercambian los discursos contradictorios de los tres actores que tienen legitimidad para expresarse públicamente sobre política, y son los políticos, los periodistas y la opinión pública a través de 
los sondeos" (Wolton, Dominique. "La comunicación política: construcción de un modelo. En Ferry, Jean-Marc et.al (1995). "El nuevo espacio público" Barcelona : Gedisa.

10. Un estudio más detallado de esta campaña se puede consultar en: Arceo Vacas, J.L. et. al (1993). Campañas electorales y publicidad política en España (1976-1991). Barcelona: ESPR-PPU, 1993 p.67-94.

11. Valero Naranjo, Rosa del Valle "De Telefónica Media a Admira Media". En Ámbitos. Revista Internacional de Comunicación, no 9-10. Años 2002-2003. Universidad de Sevilla, p. 31-65.

12. Las elecciones generales del 2000 han sido estudiadas en: Herrero, Julio César; Connolly-Ahren, Colleen, op.cit. Sobre el mismo tema en: Sádaba, Teresa; Varas, Miguel Alfonso "Elecciones 2000: Carrera de caballos y partidismo mediático". En ZER, Revista de Estudios de Comunicación, no 141, mayo 2003, p. 59-74. Facultad de Ciencias Sociales y de la Comunicación. Universidad del País Vasco. Bilbao.

13. Holgado González, María "El papel de los medios de comunicación en la campaña electoral". En Ámbitos. Revista Internacional de Comunicación, no 9-10, 2002-2003, p. 479-484. Universidad de Sevilla.

14. Sádaba, Teresa; Varas, Miguel Alfonso op.cit. p. 59-74.

15. Sobre el uso de Internet en la comunicación política en España, ver: Contijoch, Marta "L'irrupció d'Internet a la comunicación política dels partits". En Trípodos, no 17. Barcelona: Universitat Ramón Llull, 2005.

16. Arceo Vacas, J.L. et al. Op. Cit. El autor escribe en la página 73, citando un artículo del periódico El País del 1 de octubre de 1982: "Un grupo de catorce bancos financian las diversas actividades electorales del PSOE, AP, UCD. El tipo de interés ascendió al 14\%".

17. Sobre el desarrollo de la comunicación política en España ver: Aranes, José Ignacio "La comunicación institucional en la Administración pública: Entre la lógica autista-instrumental y la democracia". En ZER, Revista de estudios de comunicación. Diciembre 1996. Facultad de Ciencias Sociales y de la Comunicación. Universidad del País Vasco. Bilbao.

18. El CAC es un organismo de regulación y supervisión audiovisual, cuyas funciones se inspiran en el CSA francés. Territorialmente sus competencias se limitan a Cataluña. España no tiene un organismo de supervisión del espacio audiovisual.

19. Sobre este tema podemos ver las diferentes posiciones, a menudo contradictorias. Algunos autores llaman a la moderación y la transparencia en los gastos electorales y al mismo tiempo están a favor de que los partidos puedan comprar espacios publicitarios a las televisiones privadas. Ver: Herrero, Julio César; Connelly-Ahren, Colleen op. cit p. 164. Y ver: Holgado González, María op.cit. Esta autora defiende la prohibición de comprar espacios en televisión, basándose en el principio de igualdad de oportunidades (p. 473-474).

20. Lakoff, George "Don't think of an Elephant : Know Your Values and Frame the Debate" Windsor Country : Chelsea Green Publising, 2004.

21. El periódico digital http://www.peridistadigital.com publicó el 13 de marzo de 2006 un estudio que recogía de forma extensiva los calificativos que los máximos dirigentes del Partido Popular dijeron refiriéndose a José Luís Rodríguez Zapatero durante su primera legislatura.

Para citar este artículo:

Pere-Oriol Costa (20-06-2012). LA COMUNICACIÓN POLÍTICA EN LA ESPAÑA DEMOCRÁTICA (1976-2012).

REDMARKA - CIECID - Unidad de Investigación en Marketing Aplicado-Universidad de A Coruña

Año V, Número 8, V1, pp.83-108

ISSN 1852-2300

URL del Documento : cienciared.com.ar/ra/doc.php? $n=1656$

URL de la Revista : cienciared.com.ar/ra/revista.php?wid=39 